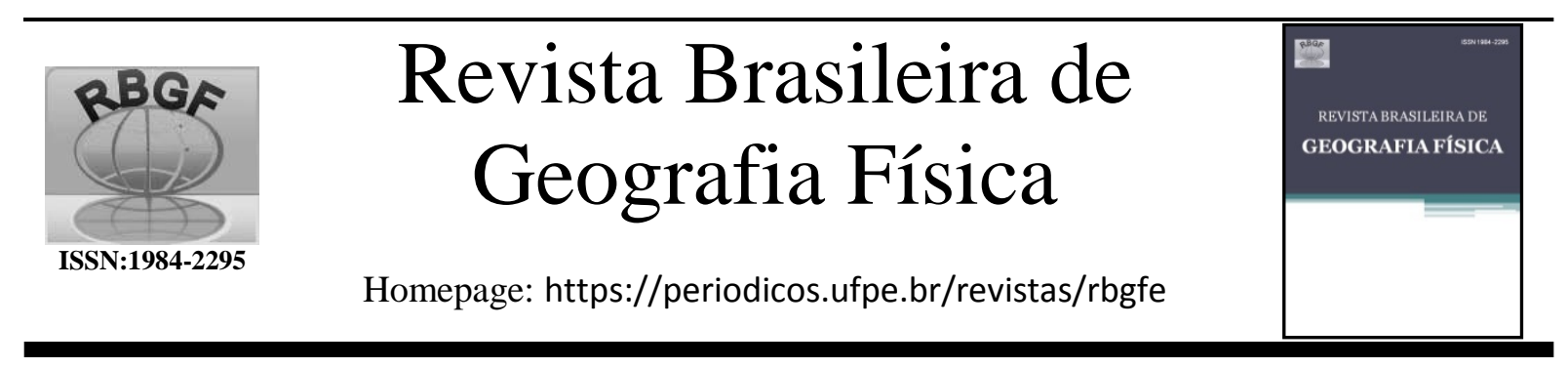

\title{
Distribuição espaço-temporal das queimadas no bioma Cerrado (1999/2018) e sua ocorrência conforme os diferentes tipos de cobertura e uso do solo
}

\author{
Maíra Iaê Savioli Rocha' ${ }^{1}$, Diego Tarley Ferreira Nascimento² \\ ${ }^{1}$ Mestranda do Programa de Pós-Graduação em Geografia da Universidade Estadual de Goiás - Campus Cora Coralina, Av. Deusdete Ferreira de \\ Moura, CEP 76600-000, Cidade de Goiás, Goiás. (62) 3371-4971. mairaa.savioli@ gmail.com. ${ }^{2}$ Doutor em Geografia, Professor Adjunto da \\ Universidade Federal de Goiás, Av. Esperança, s/n, Campus Samambaia, CEP 74690-900, Goiânia, Goiás. (62) 3521-1000. \\ diego_nascimento@ufg.com (autor correspondente).
}

Artigo recebido em 09/04/2020 e aceito em 24/04/2021

\section{RES UMO}

Usualmente empregadas pelos povos tradicionais, as queimadas também têm sido utilizadas para o desmatamento de vegetação natural e incorporação de atividades agropecuárias. Diante desse contexto, tem-se como objetivo analisar a distribuição espaço-temporal dos focos de queimadas no bioma Cerrado no período de 1999 a 2018, verificando sua ocorrência entre os diferentes tipos de cobertura e uso do solo, no intuito de avaliar a hipótese de que a prática de queimadas esteja recorrentemente associada aos desmatamentos e à implantação de atividades agropecuárias. Para tanto, foram compilados, organizados e processados em ambiente SIG os arquivos vetoriais de focos de queimadas, a partir do Banco de Dados de Queimadas do Instituto Nacional de Pesquisas Espaciais (BDQ/INPE), e arquivos matriciais de cobertura e uso do solo do Cerrado, provenientes dos mapeamentos anuais do Projeto MapBiomas, ambos dados referentes ao bioma Cerrado e ao recorte temporal de 1999 a 2018. Em termos médios, verifica-se a ocorrência de 65.513 focos anuais de queimadas, porém, em alguns anos a quantidade de queimadas atinge o montante de 137.918 focos, como visto em 2007. Há uma concentração das queimadas no período seco, especialmente, no trimestre agosto-setembrooutubro, que responde por $72 \%$ das ocorrências anuais. A maior densidade de queimadas é percebida ao longo da fronteira agrícola na região do MATOPIBA e próxima ao Arco do Desmatamento, nos estados do Maranhão, Tocantins e de Mato Grosso, ao passo que evidencia-se a maior incidência das queimadas sobre determinadas classes de cobertura e uso do solo, sobretudo representadas por formações savânicas e campestres, o que corrobora a hipótese do uso das queimadas para conversão de cobertura vegetal em usos antrópicos.

Palavras-chave: Queimadas, Cerrado, Cobertura e uso do solo.

\section{Space-temporal distribution of fires in the Cerrado biome (1999/2018) and their occurence according to different types of coverage and soil uses}

\begin{abstract}
A B S T R A C T
Usually employed by traditional communities, fires have also been used to deforest and incorporate agricultural activities. Given this context, the objective is to analyze the spatio-temporal distribution of the fires in the Cerrado biome, from 1999 to 2018, verifying their occurrence between the different types of cover and land use, in order to assess the hypotheses that the practice of fires is recurrently associated with deforestation and the implementation of agricultural activities. For this purpose, were compiled, organized and processed in a GIS environment, fires focus from the Burn Database of the National Institute for Space Research and mappings of cover and land use, elaborated and availabled by the MapBiomas Project, both data referring to the Cerrado biome and over the years 1999 to 2018. On average, there are 65,513 annual fires, but in some years the amount of burns reaches the amount of 137,918 - as seen in 2007. There is a concentration of fires in the dry period, mainly in the August-September-October, which accounts for $72 \%$ of annual fires. The highest density of fires occurs mainly along the agricultural frontier in the MATOPIBA region and close to the Arc of Deforestation, specifically in the states of Maranhão, Tocantins and Mato Grosso, while there is a greater incidence of fires on certain classes of coverage and land use, especially represented by savanna and grassland formation, which corroborates the hypothesis of the use of fires to convert vegetation cover into anthropic uses.
\end{abstract}

Keywords: Fires, Cerrado, Cover and land use. 


\section{Introdução}

O território brasileiro é composto por biomas igualmente relevantes. Entretanto, chamamos atenção para o Cerrado, não apenas pelo fato de ser o segundo maior bioma brasileiro em extensão e por ser considerado como um dos 34 hotspots existentes no planeta para a conservação da biodiversidade mundial (Mittermeier et al., 2004), mas, especialmente, por conta desse bioma ter sido o cenário de um incomparável processo de conversão de sua vegetação natural para usos antrópicos.

Dados do Projeto MapBiomas (2019) apontam para taxas de desmatamento no Cerrado historicamente superiores às da Mata Atlântica e da Floresta Amazônica, tendo em vista que no ano de 2018, cerca de $41,3 \%$ de sua cobertura natural já se encontrava convertida para usos antrópicos, tendo ocorrido especialmente no contexto dos programas implementados a partir da década de 1970 para "desenvolvimento" do Cerrado (Programa de Desenvolvimento dos Cerrados - Polocentro - e Programa de Cooperação Nipo-brasileira para o Desenvolvimento dos Cerrados - Prodecer). É a partir desse contexto, de ocupação intensificada do bioma, que a modernização e mecanização da agricultura se consolidam, criando condições para a produção de commodities (Silva, 2013). Tal processo de apropriação configurou a região do Cerrado como a principal fronteira de expansão agrícola em curso no território brasileiro.

As queimadas possuem estreita relação com o desmatamento e as atividades agropecuárias nos biomas brasileiros, e o Cerrado não foge à regra. Corriqueiramente empregadas pelos povos tradicionais, as queimadas são utilizadas para limpeza de pastos, preparo de áreas para plantio e queima de bagaços. Todavia, essa prática também tem sido usada para o desmatamento de vegetação natural para incorporação de atividades agropecuárias. Conforme indicado pela Figura 1, a Amazônia e o Cerrado despontam com as maiores quantidades de focos de queimadas dentre os biomas brasileiros, no período de 1998 a 2020. Apesar da Amazônia revelar a maior incidência de focos ao longo da série histórica considerada, o Cerrado segue em segundo lugar. Contudo, em alguns anos a quantidade de queimadas no Cerrado se aproxima da registrada na Amazônia, conforme visto em 2010, com diferença de apenas 1.220 focos, enquanto que em outros anos evidencia-se maior incidência de focos no bioma Cerrado, como registrado em 2011 e 2012, com 3.496 e 3.881 focos além dos contabilizados na Amazônia durante os referidos anos, respectivamente.

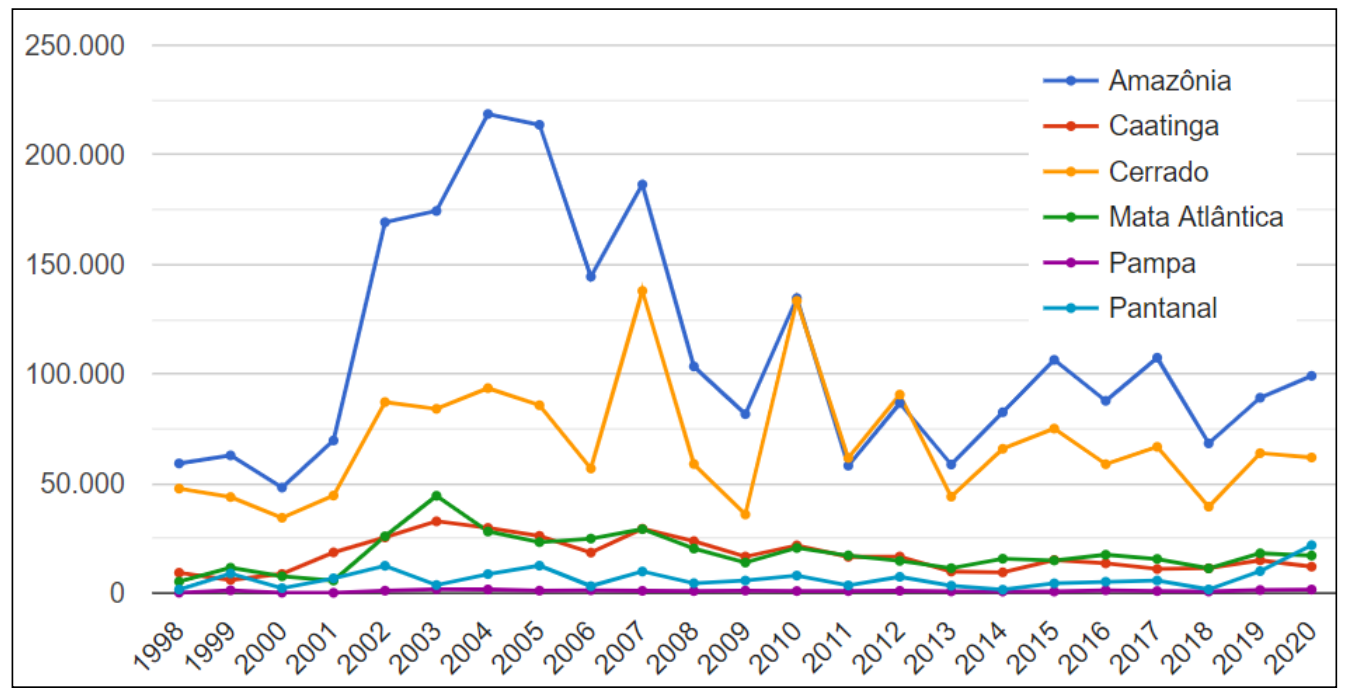

Figura 1 - Série histórica de focos de queimada por biomas brasileiros (1998 a 2020)

Fonte: http://queimadas.dgi.inpe.br/queimadas/portal-static/estatisticas_estados/.

Barbosa (2015) destaca que o fogo (natural) tem atuado há milhares de anos sob as diferentes fitofisionomias de vegetação do Cerrado, influenciando a formação e a evolução do bioma. Em fato, o Cerrado é considerado como um bioma adaptado ao fogo, com algumas de suas características sinalizando tais adaptações, a citar as cascas de árvores grossas, os frutos isolantes e as reservas subterrâneas de água (Coutinho, 2005). Além disso, o Cerrado depende do fogo para 
ocorrência de alguns processos ecológicos, como a germinação de algumas sementes que precisam do choque térmico para a quebra da dormência vegetativa (Clarke e French, 2005). Miranda e colaboradores (2002) chegam a considerar que o fogo é um fator estruturante das paisagens e determinante para alguns processos ecológicos no Cerrado.

É possível encontrar evidencias do papel do fogo na evolução do Cerrado ao analisar espécies adaptadas, como, por exemplo, a Vellozia sp., popularmente conhecida como canelade-ema (Figura 2), que é endêmica de campos rupestres e usualmente utilizada para acender fogões em comunidades tradicionais.

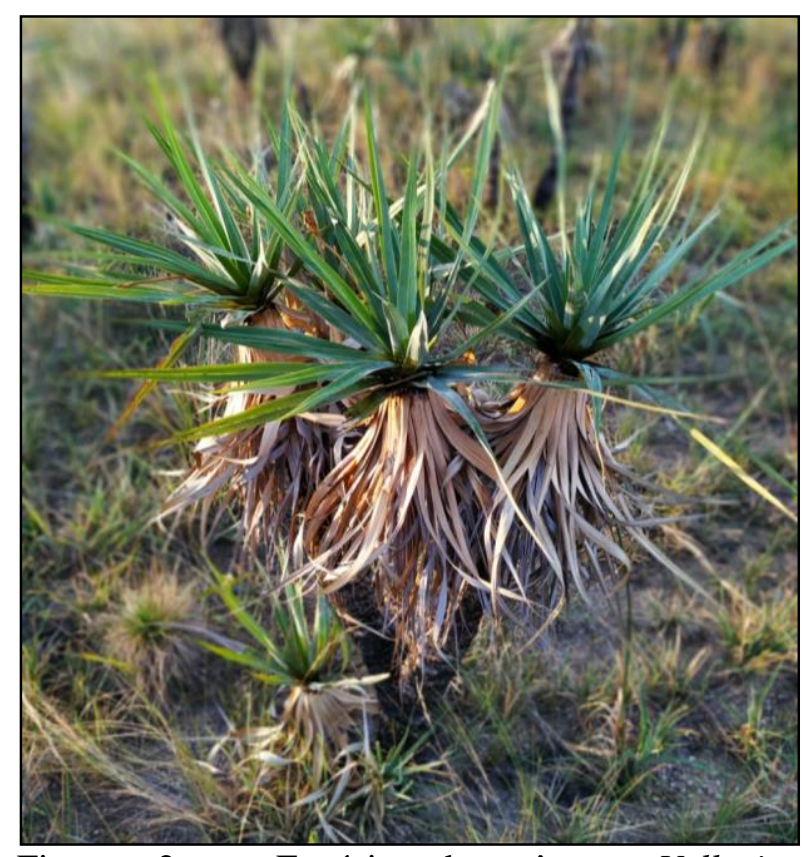

Figura 2 - Espécie do gênero Vellozia, popularmente conhecida como canela-de-ema.

Fotografia: Carlos Eduardo Félix da Silva (2019)

No entanto, a reprodução e floração de grande parte das espécies da flora do bioma podem ser prejudicadas pela alteração do regime de fogo (em termos de duração, intensidade e frequência). Temperaturas extremas e longos períodos de exposição retardam a germinação de sementes e matam espécies mais sensíveis e até mesmo as mais resistentes. Sendo assim, variar o regime de fogo significa alterar as respostas de espécies já adaptadas (Medeiros e Miranda, 2005).

A recorrência e maior intensidade das queimadas tornaram o fogo uma perturbação indesejável no sistema ecológico, repercutindo numa gama de impactos negativos, tais como a perda de biodiversidade, o aumento na suscetibilidade à erosão, a emissão de aerossóis e gases responsáveis pela intensificação do efeito estufa e a compactação e perda de nutrientes, de umidade e de biota do solo.

A alteração da frequência, da intensidade e do período de incidência das queimadas está associada, principalmente, às atividades humanas que utilizam o fogo erroneamente, desconsiderando as condições meteorológicas, as características ambientais e a fisiologia das espécies vegetais de cada ambiente. Cria-se, assim, um cenário mais suscetível às queimadas desastrosas, que passam a atingir não só as espécies herbáceas, como é comum em queimadas naturais (Miranda et al., 1993), mas também as espécies lenhosas, onde parte da fauna se refugia em eventos como esse.

A supressão absoluta do fogo no Cerrado tampouco é favorável para o equilíbrio dos processos ecológicos, tendo em vista o favorecimento, nesse caso, do adensamento da vegetação arbórea (formações florestais) em detrimento de formações mais abertas (formações savânicas e campestres). Além disso, intervalos longos entre queimadas também podem resultar em eventos mais intensos e catastróficos, devido ao acúmulo de biomassa. Há, nas duas situações, de aumento excessivo de queimadas e da tentativa de exclusão do fogo, descaracterização das fisionomias e perda de biodiversidade.

Todavia, apesar de constituir um elemento essencial para a formação, evolução e manutenção do Cerrado e utilizado como técnica no manejo da terra há milênios pelas comunidades tradicionais, $\mathrm{o}$ fogo teve seu uso subvertido pelas práticas antrópicas predatórias no âmbito do agronegócio, empregado para a abertura da fronteira agrícola e para o manejo intensificado de áreas agrícolas e de pastagens (França, 2000).

Com base em dados de focos de calor gerados pela University of Maryland (EUA), Nascimento, Araújo e Ferreira Júnior (2010) identificaram que, do total de 32.001 focos de calor localizados no bioma entre maio de 2008 e maio de 2009, 75,6\% ocorreram sob áreas ocupadas por vegetação natural (especialmente em formações savânicas), ao passo que $13,2 \%$ ocorreram em áreas de pastagens e $11 \%$ em áreas ocupadas por cultivos agrícolas. Santos, Pereira e Rocha (2014) analisaram a frequência das queimadas no Cerrado entre 2002 e 2012, e também identificaram a maior incidência de queimadas sob as formações savânicas. Dessa forma, põe-se em questão a tese de que as queimadas estão associadas a 
desmatamentos para a implantação de atividades agropecuárias, tendo em vista a recorrência dos focos sob as coberturas naturais.

Diante desse contexto, tem-se como objetivo analisar a distribuição espaço-temporal dos focos de queimadas no bioma Cerrado no período de 1999 a 2018, verificando sua ocorrência entre os diferentes tipos de cobertura e uso do solo, no intuito de avaliar a hipótese de que a prática de queimadas esteja recorrentemente associada aos desmatamentos e à implantação de atividades agropecuárias.

\section{Material e métodos}

Localização e caracterização da área em estudo

A área em estudo compreende o bioma Cerrado, circunscrito às latitudes $2^{\circ} 10^{\prime} 53^{\prime \prime}$ e $24^{\circ} 48^{\prime} 41^{\prime \prime}$ Sul e longitudes $41^{\circ} 39^{\prime} 51^{\prime \prime}$ e $60^{\circ} 13^{\prime} 18^{\prime \prime}$ Oeste, ocupando uma área de aproximadamente $2.036 .448 \mathrm{~km}^{2}$ - representando cerca de $24 \%$ do território brasileiro (IBGE, 2016).

Apesar de prevalecer a tipologia de clima tropical, quente e úmido, com chuva de verão e inverno seco (Nimer, 1989), o Cerrado possui uma grande diversidade pluviométrica e térmica, com variação crescente das chuvas no sentido leste para oeste - partindo de médias de acumulados anuais de $800 \mathrm{~mm}$, no limite com a Caatinga, alcançando os $1.831 \mathrm{~mm}$, na interface com a Amazônia, e das temperaturas em sentido sul-norte, variando entre 18 e $28^{\circ} \mathrm{C}$, da porção centro-sul de São Paulo ao norte do Maranhão (Nascimento e Novais, 2020).

Com base nas contribuições de Serra e Ratisbonna (1942), Monteiro (1951), Nimer (1979), Fonzar (1994) e Nascimento e Novais (2020), indica-se a atuação no bioma Cerrado de sistemas atmosféricos de origem equatorial e tropical, representados pela massa Equatorial continental $(\mathrm{mEc})$ e massa Tropical atlântica $(\mathrm{mTa})$, respectivamente - com a incursões da massa Polar (mP) e repercussão de sistemas perturbadores, como a Zona de Convergência do Atlântico Sul (ZCAS) e as Frentes Frias (FF). Conforme o aquecimento desigual entre as estações do ano, esses sistemas adentram a área em apreço conforme o caminho preferencial e as barreiras impostas pela topografia, e repercutem a sazonalidade climática marcante na região, de haver um período chuvoso e quente (primavera e verão), que intercala com outro seco e de temperaturas mais amenas (outono e inverno).

À título de retratação da variação mensal das chuvas e temperaturas, toma-se como exemplo as normais climatológicas de 1981 a 2010 para a estação meteorológica de Goiânia-GO (INMET, 2018), cidade situada na área core do bioma Cerrado. Conforme visto pela Figura 3, as temperaturas mais elevadas ocorrem durante os meses característicos da primavera e verão, de setembro a abril, e as menores no final do outono e inverno, de maio a agosto. Outubro representa o mês mais quente $\left(25,6^{\circ} \mathrm{C}\right)$ e junho o mês mais frio $\left(21,8^{\circ} \mathrm{C}\right)$ do ano. $\mathrm{O}$ gráfico da Figura 3 também demonstra que o período chuvoso se estende por sete meses, de outubro a abril, concentrando pouco mais de $90 \%$ do acumulado anual de precipitação, havendo uma estiagem que perdura ao longo de cinco meses, entre maio e setembro.

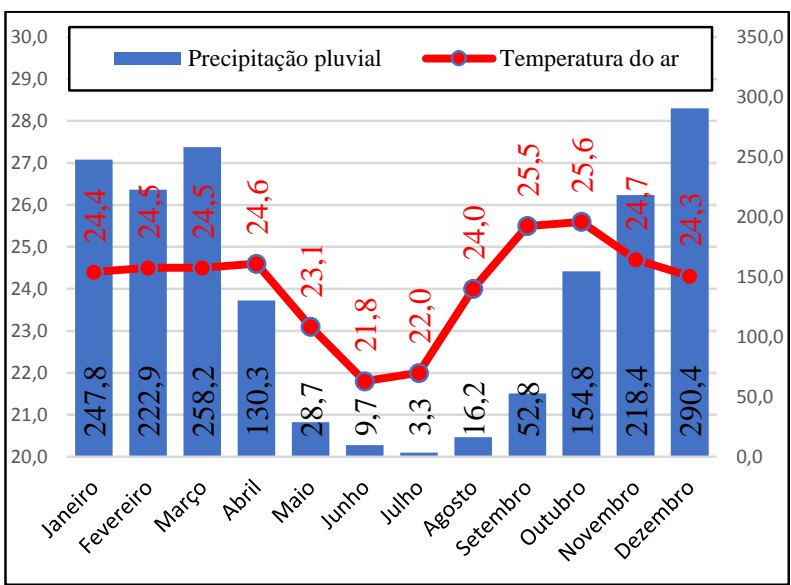

Figura 3 - Média mensal de precipitação e temperatura do ar em Goiânia-GO (1981/2010). Fonte: INMET (2018), organizado pelos autores.

A respeito de sua vegetação, o grande destaque é para a heterogeneidade das fitofisionomias do Cerrado, variando desde fisionomias campestres (campo limpo, campo sujo e campo rupestre), nas quais predominam espécies herbáceas e arbustivo-herbáceas; perpassando por formações savânicas (campo rupestre, vereda, palmeiral, parque de cerrado, cerrado ralo, cerrado típico e cerrado denso), caracterizadas pela ocorrência de estratos arbóreos, arbustivoherbáceo e árvores espalhadas, de forma descontinua, por um substrato gramíneo; e chegando a formações florestais (mata ciliar, mata de galeria, mata seca e cerradão), nas quais espécies arbóreas definem um dossel contínuo (Ribeiro e Walter, 2008).

O Cerrado é geralmente mencionado como berço das águas do Brasil, por ser o divisor de águas das três maiores redes hidrográficas brasileiras: Amazônica, Platina e do São Francisco (Nascimento, 2002), e como uma caixa-de-água do Brasil, pela importante contribuição na recarga das águas subterrâneas, com as dos aquíferos Guarani, Urucuia e Bambuí. 
A Figura 4 representa o mapeamento de cobertura e uso do solo do Cerrado para o ano de 2018, realizado e disponibilizado no âmbito do Projeto MapBiomas (2018), pelo qual observa-se que $58,7 \%$ do bioma ainda é representado por coberturas vegetais naturais, ao passo que $41,3 \%$ é ocupado por usos e atividades antrópicas. Dentre as coberturas naturais, predominam as formações savânicas $(21,5 \%)$, seguidas pelas florestais $(20,9 \%)$ e, por último, campestres (15,5\%). Dentre as áreas antropizadas, o predomínio é de pastagem $(27,6 \%)$, seguidas pelas áreas revestidas por agricultura $(12,6 \%)$ e infraestrutura urbana $(0,4 \%)$.

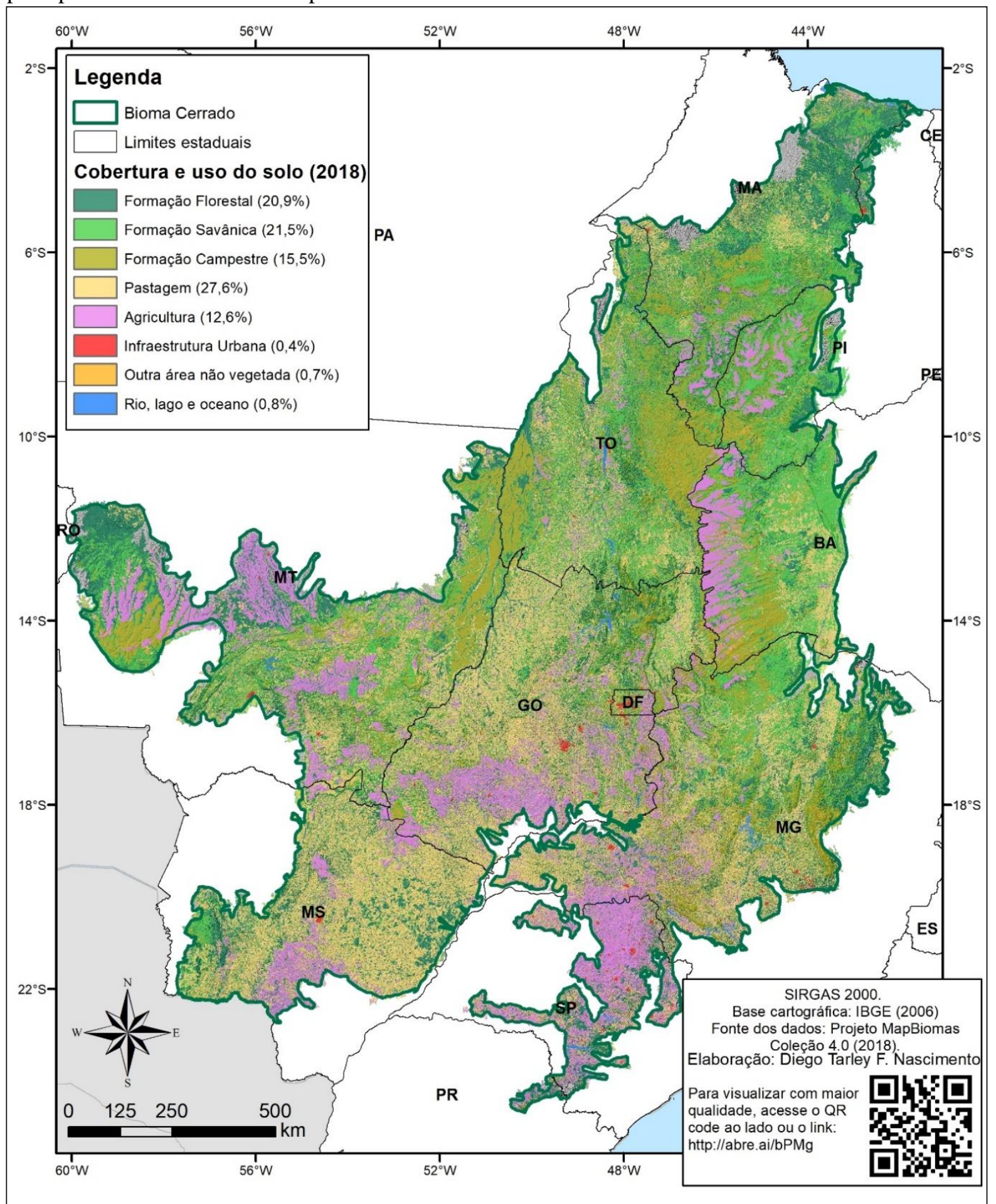

Figura 4 - Localização do bioma Cerrado e principais classes de cobertura e uso do solo (2018).

Fonte: Projeto MapBiomas - Coleção 4, organizado pelos autores. Obs.: para visualizar a imagem com maior resolução, acesse o link http://abre.ai/bPMg. 
Conforme os dados históricos do Projeto MapBiomas referentes a proporção ocupada pelas classes de cobertura e uso do dolo do Cerrado entre 1985 e 2018 - Tabela 1, percebe-se a redução de $12,8 \%$ das coberturas vegetais para implantação de atividades agropecuárias entre o período analisado. Dentre as coberturas vegetais, a formação savânica apresenta maior redução $(7,8 \%)$, seguida pela formação florestal $(3,4 \%)$. No tocante às atividades antrópicas, o maior incremento é relacionado às atividades agrícolas $(8,5 \%)$, em segunda posição constam as áreas de pastagens, com 4,8\% de ampliação nesse mesmo período.

Tabela 1 - Proporção (\%) das classes de cobertura e uso do solo do Cerrado entre 1985 e 2018.

\begin{tabular}{|l|c|c|c|}
\hline \multicolumn{1}{|c|}{ Classe } & $\mathbf{1 9 8 5}$ & $\mathbf{2 0 1 8}$ & Dinâmica \\
\hline Formação Florestal & 24,2 & 20,9 & $-3,4$ \\
\hline Formação Savânica & 29,4 & 21,5 & $-7,8$ \\
\hline Formação Campestre & 17,3 & 15,5 & $-1,8$ \\
\hline Corpos Hídricos & 0,6 & 0,8 & $+0,2$ \\
\hline Pastagem & 22,7 & 27,6 & $+4,8$ \\
\hline Agricultura & 4,1 & 12,6 & $+8,5$ \\
\hline Infraestrutura urbana & 0,1 & 0,4 & $+0,2$ \\
\hline Área não vegetada & 1,5 & 0,8 & $-0,7$ \\
\hline Cobertura natural & $\mathbf{7 1 , 5}$ & $\mathbf{5 8 , 7}$ & $\mathbf{- 1 2 , 8}$ \\
\hline Usos antrópicos & $\mathbf{2 8 , 5}$ & $\mathbf{4 1 , 3}$ & $\mathbf{+ 1 2 , 9}$ \\
\hline
\end{tabular}

Fonte: MapBiomas (2019), organizado pelos autores.

Justamente por conta dessa intensa e acelerada conversão (ainda em curso) de sua cobertura vegetal, o Cerrado é considerado como um dos 34 hotspots existentes no planeta para a conservação da biodiversidade mundial (Mittermeier et al., 2004), abrigando a mais rica flora dentre as savanas no mundo e uma grande diversidade de espécies de peixes, aves, répteis, insetos e anfíbios (Klink e Machado, 2005).

\section{Procedimentos metodológicos}

Basicamente, os procedimentos metodológicos consistiram em aquisição e análise de dados secundários. A partir do Banco de Dados de Queimadas do Instituto Nacional de Pesquisas Espaciais (BDQueimadas/INPE), foram compiladas as estatísticas mensais e anuais, em formato tabular, e adquiridos os focos, em formato vetorial, das queimadas registradas no Cerrado entre 1999 e 2018.
Os dados foram tratados em planilha de Excel do Microsoft Office versão 2016, pela qual foram aplicadas técnicas estatísticas (de medidas de posição e dispersão) para subsidiar a descrição da distribuição temporal.

Em seguida, os arquivos vetoriais foram dispostos em ambiente de Sistema de Informações Geográficas (SIG), especificamente no software ArcGIS, versão 10.3, para quantificação dos focos de queimadas por unidade federativa e estimativa da densidade espacial pelo método de kernel, para subsidiar a análise da distribuição espacial das queimadas no bioma Cerrado.

Com vistas a retratar a ocorrência das queimadas segundo as classes de cobertura e uso do solo, foram obtidos os arquivos matriciais dos mapeamentos anuais de cobertura e uso do solo do Cerrado, entre 1999 e 2018, elaborados e disponibilizados pelo Projeto MapBiomas (2019), coleção 4.0. Esses arquivos também foram dispostos ao projeto concebido no ArcGIS, baseado no sistema de referência geodésico SIRGAS 2000.

Por meio da ferramenta de análise espacial de extração de atributos por pontos, as informações das classes de cobertura e uso do solo foram automaticamente inseridas à tabela de atributos dos focos de queimadas, tendo como base a localização de cada ponto das queimadas anuais sobre os mapeamentos também anuais de cobertura e uso do solo. Por fim, se procedeu à elaboração das representações tabulares, gráficas e cartográficas e à realização da correspondente análise e interpretação dos dados.

Destaca-se que na interceptação verificouse que alguns focos de queimadas do BDQueimadas/INPE não coincidiram com $o$ arquivo de cobertura e uso do solo proveniente do Projeto Mapbiomas, possivelmente, por conta de diferentes limites que os órgãos consideram para o bioma Cerrado. Portanto, na correlação dos focos conforme as distintas classes de cobertura e uso do solo foram considerados totais anuais de queimadas inferiores daqueles registrados e divulgados pelo INPE para o Cerrado - sendo a diferença absoluta e proporcional indicada pela Tabela 2. Nas demais análises (distribuição mensal e anual para o bioma, quantificação por Unidade Federativa e densidade espacial) foram utilizados os totais anuais de focos conforme divulgado pelo INPE. 
Tabela 2 - Focos de queimadas registrados e divulgados pelo BDQueimadas/INPE e a proporção coincidente ao mapeamento de cobertura e uso do solo do MapBiomas.

\begin{tabular}{|l|r|r|r|r|}
\cline { 2 - 5 } \multicolumn{1}{c|}{ Ano } & $\begin{array}{c}\text { Total anual de focos } \\
\text { do BDQueimadas }\end{array}$ & $\begin{array}{c}\text { Total coincidente com o mapeamento de } \\
\text { cobertura e uso do solo do MapBiomas }\end{array}$ & $\begin{array}{c}\text { Diferença entre o } \\
\text { total e o coincidente }\end{array}$ & $\begin{array}{c}\text { \% da diferença entre o } \\
\text { total e o coincidente }\end{array}$ \\
\hline $\mathbf{1 9 9 9}$ & 43.850 & 41.422 & 2.428 & 5,5 \\
\hline $\mathbf{2 0 0 0}$ & 34.393 & 32.212 & 2.181 & 6,3 \\
\hline $\mathbf{2 0 0 1}$ & 44.534 & 41.707 & 2.827 & 6,3 \\
\hline $\mathbf{2 0 0 2}$ & 78.719 & 74.172 & 4.547 & 5,8 \\
\hline $\mathbf{2 0 0 3}$ & 84.113 & 78.717 & 5.396 & 6,4 \\
\hline $\mathbf{2 0 0 4}$ & 93.562 & 87.208 & 6.354 & 6,8 \\
\hline $\mathbf{2 0 0 5}$ & 85.747 & 80.257 & 5.490 & 6,4 \\
\hline $\mathbf{2 0 0 6}$ & 56.880 & 53.855 & 3.025 & 5,3 \\
\hline $\mathbf{2 0 0 7}$ & 137.918 & 131.697 & 6.221 & 4,5 \\
\hline $\mathbf{2 0 0 8}$ & 58.934 & 56.108 & 2.826 & 4,8 \\
\hline $\mathbf{2 0 0 9}$ & 35.899 & 34.013 & 1.886 & 5,3 \\
\hline $\mathbf{2 0 1 0}$ & 133.394 & 129.034 & 4.360 & 3,3 \\
\hline $\mathbf{2 0 1 1}$ & 61.682 & 59.356 & 2.326 & 3,8 \\
\hline $\mathbf{2 0 1 2}$ & 90.600 & 87.414 & 3.186 & 3,5 \\
\hline $\mathbf{2 0 1 3}$ & 44.017 & 41.987 & 2.030 & 4,6 \\
\hline $\mathbf{2 0 1 4}$ & 65.871 & 63.366 & 2.505 & 3,8 \\
\hline $\mathbf{2 0 1 5}$ & 75.094 & 72.642 & 2.452 & 3,3 \\
\hline $\mathbf{2 0 1 6}$ & 58.833 & 56.542 & 2.291 & 3,9 \\
\hline $\mathbf{2 0 1 7}$ & 66.762 & 63.966 & 2.796 & \\
\hline $\mathbf{2 0 1 8}$ & 39.449 & 37.746 & 1.703 & \\
\hline
\end{tabular}

Fonte: BDQueimadas/INPE e Mapbiomas, calculado em SIG e organizado pelos autores

\section{Resultado e discussão}

Distribuição temporal dos focos de queimadas no bioma Cerrado

A quantidade média de queimadas anuais no Cerrado, tendo como base os anos analisados, é de 69.513 focos, com mediana bem próxima, referente a 63.777 focos. O desvio padrão das quantidades anuais de queimadas é de 29.058 focos - valor esse que representa quase metade da média e mediana, o que demonstra uma considerável variabilidade anual das queimadas no Cerrado.

O histograma representado pela Figura 5 indica uma maior frequência de anos em que são registrados entre 55.099 e 75.803 focos de queimadas, seguido de perto por anos com quantidades logo abaixo (34.393 a 55.098) ou acima (75.804 a 96.508) desse patamar. O referido histograma indica uma distribuição assimétrica à direita das queimadas registradas no Cerrado entre 1999 e 2018, tendente às menores quantidades anuais de queimadas, que pode ser justificada pela ocorrência de poucos anos com valores extremos e anômalos de quantidade de queimadas, conforme visto nos anos de 2007 (com 137.918 focos) e 2010 (com 133.394 focos).

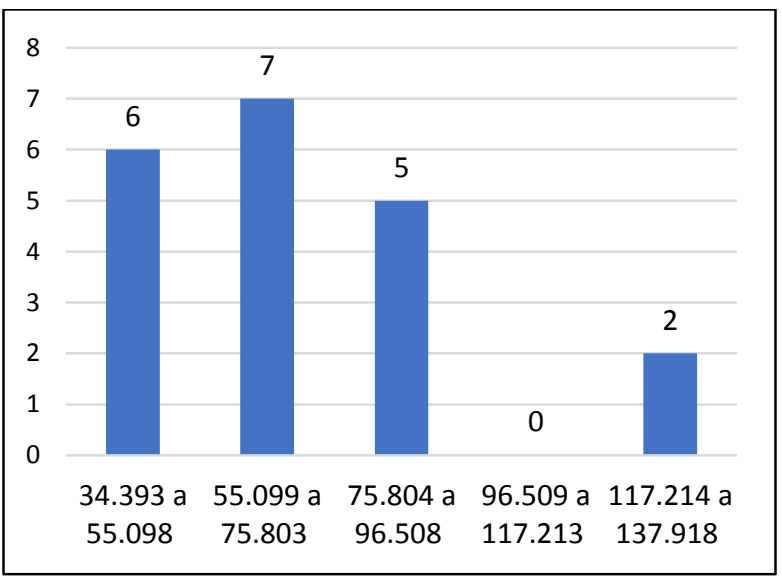

Figura 5 - Histograma de frequência de focos de queimadas no bioma Cerrado (1999 e 2018)

Fonte: BDQueimadas/INPE, organizado pelos autores.

Dentre os vinte anos analisados, apenas oito apresentam quantidade anual de queimadas acima do valor médio (69.513 focos), o que representa menos da metade do recorte temporal (40\%). Por sua vez, doze anos (60\%) apresentam quantidade abaixo do valor médio de queimadas Figura 6. $\mathrm{O}$ ano com maior registro de queimadas é 2007, com 137.918 focos, acompanhado de perto por 2010, com 133.394 focos. Em contrapartida, os anos de 2000 e 2009 registram as menores ocorrências de queimadas, com 34.393 e 35.899 focos, respectivamente. A amplitude entre os anos de 2007 e 2000 é de 103.525 focos. 


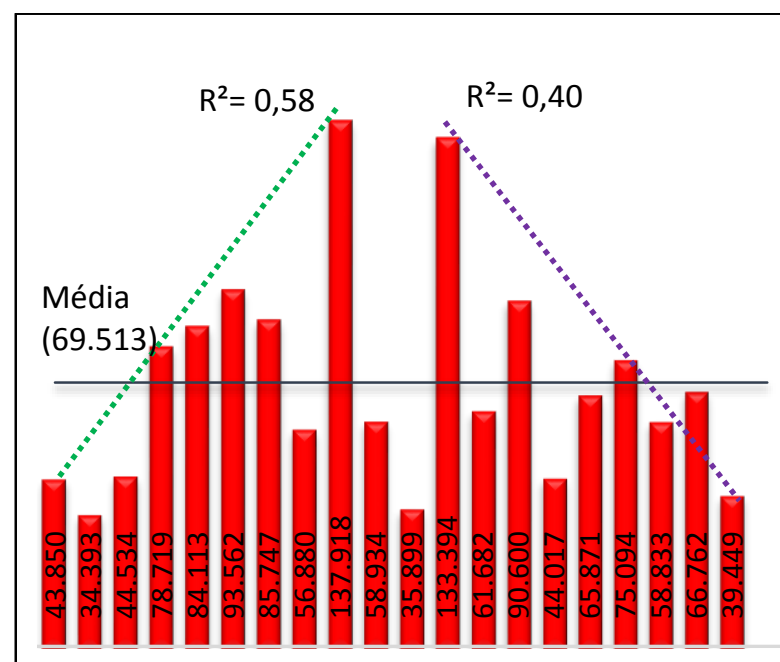

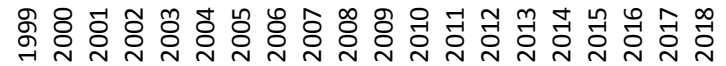

Figura 6 - Distribuição da quantidade anual de queimadas no bioma Cerrado entre 1999 e 2018

Fonte: BDQueimadas/INPE, organizado pelos autores.

Conforme ainda visto pelo gráfico da Figura 6, os dados não demonstram uma tendência estatisticamente significativa de aumento ou diminuição na quantidade anual de queimadas no Cerrado entre 1999 e 2018. Todavia, ao considerar o período de 1999 a 2007 (linha tracejada verde), percebe-se uma tendência com significância moderada de elevação da quantidade de queimadas $\left(R^{2}\right.$ de 0,58). Por sua vez, entre 2009 e 2018 (linha tracejada roxa), percebe-se uma tendência com significância moderada de diminuição das queimadas no Cerrado $\left(R^{2}\right.$ de 0,4$)$.

Possivelmente, a interrupção do aumento das queimadas em 2007 e a posterior diminuição a partir de 2010 sejam fruto do Programa de Redução do Desmatamento e das Queimadas no Cerrado Brasileiro, implementado em 2010, no âmbito do Plano de Ação para Prevenção e Controle do Desmatamento e das Queimadas no Cerrado PPCerrado. Ao longo das 3 fases do Plano (20102011, 2014-2015 e 2016-2020) foram evidenciados resultados importantes no tocante à ações de fiscalização, redução, prevenção, controle e monitoramento das queimadas no Cerrado (MMA, 2010; 2014; 2016).

A partir da interpretação da Figura 7, percebe-se que distribuição mensal das queimadas tem forte dependência com a sazonalidade das chuvas no Cerrado. Isso porque os cinco meses que caracterizam o período de estiagem na região (maio-setembro) respondem por cerca de $71 \%$ dos focos registrados durante todo o ano, enquanto os sete meses do período chuvoso se relacionam a cerca de apenas 29\% das ocorrências de queimadas. Em alguns anos, conforme registrado em 2010, o período seco responde por $82 \%$ da quantidade anual de queimadas.

\begin{tabular}{|c|c|c|c|c|c|c|c|c|c|c|c|c|c|c|}
\hline Ano & Jan & Fev & Mar & Abr & Mai & Jun & Jul & Ago & Set & Out & Nov & Dez & Total & ENOS \\
\hline 1999 & 188 & 469 & 82 & 382 & 856 & 1.757 & 3.465 & 11.933 & 14.455 & 8.354 & 1.434 & 475 & & La Niña \\
\hline 2000 & 36 & 89 & 114 & 253 & & 556 & .530 & 6.995 & 0.117 & 9.038 & .149 & 372 & & \\
\hline 001 & 82 & 109 & 69 & 304 & 713 & 606 & 3.242 & 9.541 & 6.623 & 7.702 & .834 & 609 & & \\
\hline 02 & 68 & 55 & 391 & 777 & .884 & 210 & 7.462 & 7.815 & .105 & 16.744 & 273 & .802 & & \\
\hline & 4 & 37 & 472 & 1.052 & 475 & 079 & 0.477 & .140 & 9.227 & .008 & 763 & 179 & & \\
\hline & 52 & 376 & 73 & 970 & 975 & 047 & 8.804 & 2.473 & 3.509 & 48 & 243 & 792 & & \\
\hline & & 8 & 36 & 1.071 & 968 & 383 & 454 & 4.627 & 521 & 23.550 & 251 & & & \\
\hline 6 & 001 & 413 & 498 & 584 & 1.650 & 3.415 & 6.442 & 11.705 & 16.566 & 7.524 & 5.274 & 808 & & Viña \\
\hline & 755 & 402 & 1.118 & 964 & 2.924 & 7.051 & 10.548 & 35.678 & 49.980 & 22.008 & 4.939 & .551 & & Niño \\
\hline & 21 & 321 & 339 & 590 & 1.320 & 2.632 & 5.229 & 8.643 & 15.477 & 17.024 & 5.486 & .452 & & a Niña \\
\hline & 676 & 403 & 461 & 448 & 836 & 1.641 & 4.224 & 6.492 & 9.851 & 5.526 & 4.195 & .146 & & a Niña \\
\hline & 17 & 751 & 883 & 1.438 & 2.508 & 6.443 & 12.359 & 35.226 & 52.491 & 14.419 & 4.623 & .536 & & I Niño \\
\hline 2 & 156 & 321 & 308 & 703 & 1.376 & 3.378 & 5.366 & 11.387 & 26.468 & 7.656 & 2.889 & 1.374 & & a Niña \\
\hline 2 & & 478 & 764 & 1.092 & 1.896 & 3.817 & 9.362 & 22.737 & 30.053 & 16.515 & 1.830 & 635 & & La Niña \\
\hline & & 604 & 613 & 706 & 1.418 & 2.684 & 4.761 & 8.496 & 12.615 & 7.696 & 2.370 & .579 & & Neutro \\
\hline 2 & 567 & 315 & 497 & 897 & 1.673 & 3.849 & 6.220 & 15.525 & 15.523 & 16.357 & 3.085 & .363 & & Neutro \\
\hline 201 & 096 & 383 & 528 & 634 & 1.174 & 3.313 & 4.662 & 12.684 & 23.795 & 19.531 & 4.731 & 2.563 & & Niño \\
\hline 20 & 392 & 1.048 & 767 & 1.449 & 1.782 & 3.187 & 8.675 & 13.730 & 13.256 & 9.968 & 3.647 & 932 & & I Niño \\
\hline 20 & & 376 & 687 & 696 & 1.428 & 2.858 & 6.258 & 10.815 & 26.975 & 12.393 & 2.345 & .440 & & Niña \\
\hline & & 235 & 842 & 54 & 1.729 & 2.922 & 5.220 & 7.992 & 11.467 & 5.041 & 1.763 & 1.168 & & La Niña \\
\hline & & 89 & 69 & & 713 & 1.641 & 2.530 & 6.492 & 9.851 & 5.041 & 1.149 & 372 & & - \\
\hline & 1.096 & 1.048 & 1.118 & 1.449 & 2.975 & 7.079 & 12.359 & 35.678 & 52.491 & 23.550 & 8.243 & .792 & & - \\
\hline lédia & 534 & 445 & 537 & 778 & 1.675 & 3.841 & 6.638 & 14.232 & 23.154 & 12.860 & 3.756 & 1.485 & 69.513 & - \\
\hline
\end{tabular}

Figura 7 - Distribuição mensal e anual dos focos de queimadas no Cerrado e atuação do fenômeno El NiñoOscilação Sul (ENOS) entre 1999 e 2018

Fonte: BDQueimadas/INPE e Golden Gate Weather Service, organizado pelos autores. 
O trimestre consecutivo agosto-setembrooutubro representa a maior incidência de queimadas no Cerrado, com média de $72 \%$ da quantidade anual de queimadas, chegando a representar 82\%, como visto em 2002. Esse período condiz com o final da estiagem e o retorno das chuvas, momento que há a renovação de pastos, o preparo de áreas de plantio e a queima de bagaços. Nesse trimestre, merecido destaque deve ser dado ao mês de setembro, com média de 33,3\% das ocorrências anuais de queimadas, mas chegando a registrar $43 \%$, conforme vislumbrado em 2011. Todavia, em alguns anos observa-se a maior ocorrência de queimadas em agosto (2014 e 2016) ou outubro (2008 e 2014).

Ainda pela Figura 7 percebe-se uma certa relação das menores quantidades anuais de queimadas no Cerrado com a fase negativa (La Niña) do fenômeno El Niño-Oscilação Sul ENOS, tendo em vista que nove dos doze anos com quantidade anual de queimadas abaixo da média estiveram sob atuação de La Niña (1999, 2000, 2001, 2006, 2008, 2009, 2011, 2017 e 2018). Uma relação semelhante se dá com os anos com maiores quantidades de queimadas e a fase positiva do ENOS (El Niño), sendo que cinco dos oito anos com quantidade de queimadas acima da média se correlacionam com atuação do El Niño, sendo eles: 2003, 2005, 2007, 2010 e 2015 - com dois anos retratando os maiores registros de queimadas no bioma (2007 e 2010).

Outra associação passível de ser avaliada é aquela entre as precipitações e incidência de queimadas. Dentre o recorte temporal analisado, há evidencias de relação entre a maior quantidade de queimadas $e$ as anomalias negativas de precipitação anual, o que pode ser verificado nos anos de 2007, 2010, 2012 e 2015, tendo como base a climatologia de referência do Instituto Nacional de Meteorologia (INMET, 2018). Por sua vez, nos anos de 2000, 2009, 2013, 2006, 2008 e 2011, verifica-se associação entre as menores quantidades de queimadas e anomalias positivas de precipitação na região do Cerrado. Contudo, essa associação entre a quantidade de queimada e as anomalias de precipitação (respectivamente) se mantêm em apenas metade dos anos analisados, o que não representa uma relação causal estatisticamente significativa entre as chuvas e queimadas no Cerrado. Dessa forma, sugere-se pesquisas verticalizadas, inclusive que considere as anomalias mensais do regime de chuva.

\section{Distribuição espacial dos focos de queimadas no bioma Cerrado}

A Figura 8 mostra a distribuição dos focos de queimadas entre as unidades federativas nas quais se estende o bioma Cerrado, pela qual percebe-se maior incidência de queimadas no Maranhão, com média de 17.425 focos, seguidos pelos estados de Tocantins e Mato Grosso, com 12.737 e 12.035 focos por ano, respectivamente. Também apresentam quantidades consideráveis de queimadas os estados da Bahia, de Goiás, de Minas Gerais e do Piauí, com médias anuais de focos variando entre 6.284 e 5.247 .

Os estados de Roraima, Paraná e São Paulo apresentam irrisória quantidade de focos, obviamente, por conta da coincidência do Cerrado em pouca proporção territorial dessas unidades federativas, especialmente, nos dois primeiros estados. Por outro lado, a pouca proporção de focos no Distrito Federal pode ser justificada pela sua pequena área territorial com relação à das demais unidades federativas.

Ao longo da série temporal considerada no presente estudo, o estado do Maranhão desponta com as maiores quantidade anuais de queimadas, com exceção dos anos de 1999, 2000 e 2004, quando os maiores registros ocorreram no estado do Mato Grosso.

É possível perceber que entre 1999 e 2007 há um gradativo incremento das queimadas na maioria das unidades federativas, com maior ênfase nos estados do Maranhão, Mato Grosso e Tocantins. É também notório o declínio da ocorrência de queimadas após o ano de 2010, especialmente no Mato Grosso, e mais suavemente no Maranhão e Tocantins.

Esse padrão fica mais evidente pela coleção de mapas representada na Figura 9. Apesar de haver redução/aumento nos quantitativos e algumas variações espaciais em determinados anos, é possível verificar a correspondência da maior proporção de queimadas em regiões reconhecidas pelo seu histórico de ocupação e desmatamento. 


\begin{tabular}{|c|c|c|c|c|c|c|c|c|c|c|c|c|c|}
\hline Ano & BA & DF & GO & MA & MG & MS & MT & $\mathbf{P I}$ & PR & RO & SP & TO & Total \\
\hline 1999 & 2.444 & 45 & 4.879 & 4.518 & 3.350 & 6.842 & 11.914 & 1.285 & 56 & - & 2.701 & 5.815 & 43.849 \\
\hline 2000 & 371 & 48 & 3.743 & 4.412 & 2.873 & 1.812 & 7.421 & 1.693 & 44 & - & 2.246 & 5.730 & 34.393 \\
\hline 2001 & 393 & 66 & 3.860 & 10.579 & 2.323 & 1.818 & 9.454 & 2.792 & 32 & 1 & 1.508 & 7.708 & 44.534 \\
\hline 2002 & 7.778 & 152 & 8.616 & 18.862 & 6.901 & 3.563 & 13.855 & 5.200 & 126 & 5 & 870 & 12.791 & 78.719 \\
\hline 2003 & 6.833 & 161 & 6.777 & 22.258 & 9.462 & 2.574 & 18.286 & 4.474 & 205 & 10 & 1.812 & 11.261 & 84.113 \\
\hline 2004 & 419 & 313 & 8.911 & 1.943 & 7.929 & 2.933 & 22.971 & 4.942 & 122 & 29 & 1.653 & 14.397 & 562 \\
\hline 2005 & 8.422 & 141 & 6.053 & 22.632 & 7.221 & 3.606 & 14.950 & 6.105 & 124 & 7 & 1.451 & 15.035 & 85.747 \\
\hline 2006 & 4.213 & 140 & 4.302 & 15.249 & 4.935 & 2.570 & 9.819 & 3.666 & 76 & 3 & 2.115 & 9.792 & 56.880 \\
\hline 2007 & 16.089 & 485 & 12.485 & 32.126 & 12.248 & 3.926 & 24.303 & 10.372 & 43 & 13 & 1.662 & 24.166 & 137.918 \\
\hline 2008 & .662 & 201 & 5.147 & 14.173 & 6.094 & 1.852 & 8.898 & 3.447 & 40 & 11 & 1.181 & 10.228 & \\
\hline 2009 & 2.880 & 100 & 2.787 & & 2.448 & 871 & 4.537 & 3.064 & 19 & 5 & 800 & 6.043 & 899 \\
\hline 2010 & 10.237 & 615 & 13.114 & 28. & 8.442 & 2.989 & 26.557 & 11.455 & 29 & 18 & 3.320 & 27.977 & 394 \\
\hline 2011 & 7.847 & 271 & 5.630 & 14.215 & 6.621 & 1.736 & 6.425 & 6.877 & 25 & 2 & 1.779 & 10.254 & 682 \\
\hline 2012 & 10.873 & 169 & 5.907 & 26.990 & 5.941 & 997 & 10.484 & 9.287 & 24 & - & 1.290 & 18.638 & 90.600 \\
\hline 2013 & 3.065 & 105 & 2.922 & 12.903 & 3.107 & 1.326 & 6.302 & 3.709 & 17 & - & 993 & 9.567 & 44.017 \\
\hline 2014 & 4.106 & 241 & 5.766 & 18.715 & 6.092 & 966 & 8.740 & 5.637 & 33 & 5 & 2.019 & 13.551 & 65.871 \\
\hline 2015 & 095 & 156 & 5.955 & & & 1.421 & 8.635 & 8.598 & 15 & 6 & 654 & 15.194 & \\
\hline 2016 & 2.623 & 232 & 4.710 & & 3.907 & 1.688 & & 3.363 & 32 & 10 & 1.089 & 003 & 833 \\
\hline 2017 & 3.258 & 287 & 6.202 & 19.392 & 4.702 & 1.529 & 10.768 & 4.133 & 25 & 11 & 1.624 & 14.831 & 66.762 \\
\hline 2018 & 2.075 & 88 & 2.936 & 11.286 & 2.576 & 1.042 & 5.762 & 4.850 & 13 & 2 & 1.067 & 7.752 & 39.449 \\
\hline Mínimo & 2.075 & 45 & 2.787 & 4.412 & 2.323 & 871 & 4.537 & 1.285 & 13 & - & 654 & 5.730 & 34.393 \\
\hline Máximo & 16.089 & 615 & 13.114 & 32.126 & 12.248 & 6.842 & 26.557 & 11.455 & 205 & 29 & 3.320 & 27.977 & 137.918 \\
\hline Média & 6.284 & 201 & 6.035 & 17.425 & 5.592 & 2.303 & 12.035 & 5.247 & 55 & 7 & 1.592 & 12.737 & 69.513 \\
\hline
\end{tabular}

Figura 8 - Distribuição dos focos de queimadas por unidades federativas no Cerrado entre 1999 e 2018.

Fonte: BDQueimadas/INPE, calculado em SIG e organizado pelos autores.

Maranhão e Tocantins constituem, junto ao Piauí e à Bahia, a região denominada pelo acrônimo MATOPIBA, considerada como a mais recente fronteira de expansão agrícola do Brasil, por conta de seu potencial e uso de tecnologia na produção de commodities. Por tal motivo, esses estados despontam a maior quantidade de focos de queimadas, com pouca diminuição nos últimos anos, tendo em vista representar uma região com um intenso e contínuo processo de conversão da vegetação em usos antrópicos.

No Mato Grosso há outra fronteira de expansão agrícola, reconhecida como o Arco do Desmatamento (Nogueira et al., 2007, 2008), termo utilizado em alusão à intensa devastação das paisagens naturais dessa área de transição (ecótono) entre Cerrado, Amazônia e Pantanal, que abriga rica biodiversidade de fauna e flora.

É possível deduzir que as queimadas estejam acompanhando o deslocamento e a expansão das citadas fronteiras agrícolas, sobretudo, tendo em vista que o fogo é utilizado como ferramenta de manejo em práticas agropastoris. Em estudo sobre a dinâmica da fronteira agrícola no Cerrado brasileiro, Vieira Filho (2016) indica que a ocupação e exploração agrícola no Cerrado se deu, inicialmente, nos estados da região Sul (1970), em seguida, na região Centro-Oeste (1980) e, posteriormente, sobre o MATOPIBA (1990/2000).

Uma análise comparativa dos mapas da Figura 9 permite constatar, na porção setentrional do bioma (especificamente, ao norte do paralelo de $15^{\circ} \mathrm{S}$ ), o predomínio das duas classes com maior densidade de focos ao longo dos sucessivos anos analisados, representadas pelas tonalidades escuras e relacionadas à incidência superiores a 301 focos - que chegam a alcançar 5.368 focos. Por conseguinte, com algumas exceções, na porção meridional do bioma verifica-se o predomínio das classes com menores densidades de queimadas, 1 a 100 e 101 a 300 focos.

Nos três primeiros anos da série analisada (1999 a 2001), percebe-se a predominância das duas classes com menores densidades de focos ( $<300$ focos) em quase todo o bioma, com sucessivo incremento da classe de menor densidade de focos $(<100)$. Contudo, entre 2002 e 2005 essas classes tendem a recuar, em termos de extensão, dando espaço às classes com densidade superiores a 301 focos, com maior ênfase para a classe com densidade superior à 501 focos, que chega a representar metade da área do bioma, conforme visto em 2004 e 2005. 


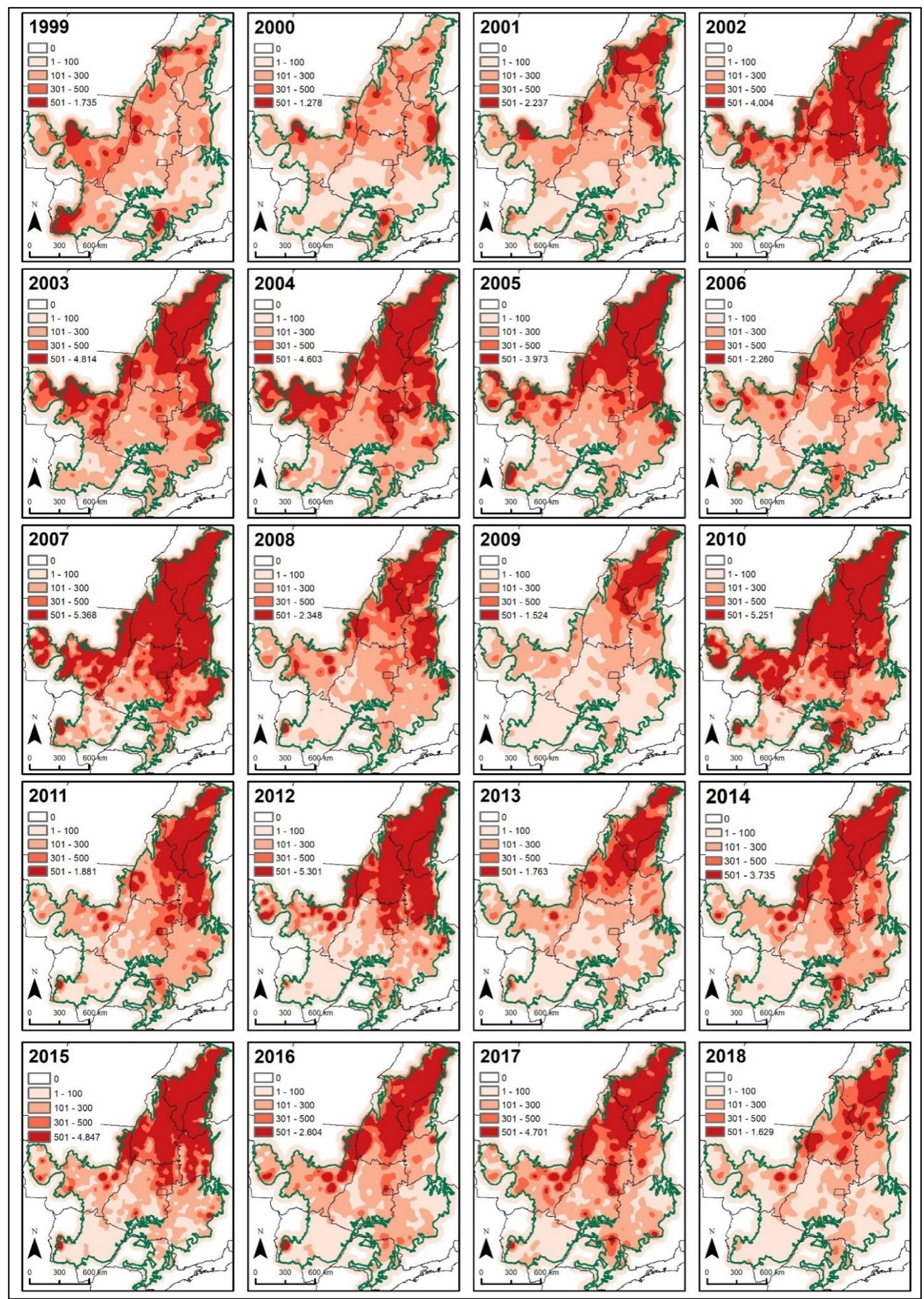

Figura 9 - Densidade espacial de incidência de focos de queimadas no bioma Cerrado entre 1999 e 2018. Fonte: BDQueimadas/INPE, calculado em SIG e organizado pelos autores. Obs.: para visualizar com maior detalhe, acesse o link: http://abre.ai/aQPw 
Em 2006 há redução da densidade de queimadas no Cerrado, mas um cenário inverso se verifica no ano seguinte (2007), quando a classe de maior densidade de queimadas passa a ocupar mais da metade do bioma. Nos dois anos que seguem, há novamente uma diminuição de queimadas, com a classe de densidade superior a 300 focos se restringindo ao norte do Cerrado, sobre Tocantins, Bahia, Maranhão e Piauí - região do MATOPIBA. No ano de 2010 voltam a predominar as classes com maiores densidade de queimadas, num padrão bastante similar ao verificado em 2007 - valendo lembrar que esses dois anos se referem à maior quantidade de focos de queimadas registrados no Cerrado.

Nos demais anos da série temporal - 2011 a 2018, percebe-se a predominância das classes com maior densidade de queimadas na porção norte do Bioma (MATOPIBA) e nas porções nordestes de Goiás (Vão do Paranã) e do Mato Grosso (ecótono entre o Cerrado e Amazônia).

Ocorrência dos focos de queimadas no bioma Cerrado conforme diferentes tipos de cobertura e uso do solo

Apesar do Projeto MapBiomas demonstrar que, em 2018, predominam no Cerrado, em ordem decrescente, as classes de Pastagem (27,6\%), Formação Savânica (21,5\%), Formação Florestal $(20,9 \%)$, Formação Campestre $(15,5 \%)$ e Agricultura (12,6\%), em termos médios, as classes de cobertura e uso do solo com maior incidência de focos são, respectivamente, as formações savânica (32\%), campestre (22\%) e florestal (21\%), seguidas pelos usos antrópicos de pastagem (16\%) e cultura agrícola (7\%) - Tabela 3.

Tabela 3 - Proporção média de queimadas que incidem sobre as principais classes de cobertura do solo (1999/2018).

\begin{tabular}{|l|c|}
\hline \multicolumn{1}{|c|}{ Classes } & $\begin{array}{c}\text { \% de } \\
\text { incidência } \\
\text { de focos }\end{array}$ \\
\hline Formação Florestal & 20 \\
\hline Formação Savânica & 32 \\
\hline Formação Campestre & 22 \\
\hline Pastagem & 16 \\
\hline Agricultura & 7 \\
\hline Outras coberturas naturais & 1 \\
\hline Outras coberturas antrópicas & 2 \\
\hline Total coberturas naturais & $\mathbf{7 6}$ \\
\hline Total usos antrópicos & $\mathbf{2 4}$ \\
\hline
\end{tabular}

Fonte: BDQueimadas/INPE e Mapbiomas, calculado em SIG e organizado pelos autores.
Importante destacar que cerca de $76 \%$ das queimadas no Cerrado incidem sobre as coberturas naturais, enquanto que apenas $24 \%$ ocorrem sobre os usos antrópicos. Dessa forma, destaca-se que a distribuição espacial das queimadas no bioma não se dá de forma aleatória e homogênea, mas associada, principalmente, às coberturas naturais propícias ao desmatamento e à implantação de atividades agropecuárias.

Conforme representado pela Figura 10, com exceção do ano de 1999, quando se registra uma pequena maior incidência de queimadas sobre áreas revestidas por pastagens (27\%), em todos os demais 19 anos analisados a maior ocorrência de focos se dá sobre formações vegetais savânicas.

Até o ano de 2003 as formações florestais respondiam pela segunda maior incidência de queimadas. Junto com as formações savânicas, respondia por cerca de metade das queimadas no Cerrado (exatamente, entre 47 e 58\%). Após esse ano, a maior proporção passa a ocorrer sobre as formações campestres. O que chama a atenção é o fato desta classe ser verificada em extensas machas, conforme visto nas porções nordeste de Goiás, noroeste de Mato Grosso e sudoeste e leste de Tocantins, tornando-a bastante suscetível à ocorrência de queimadas, especialmente, por conta do predomínio de gramíneas que servem como material combustível e pela topografia que favorece a propagação do fogo pela ação do vento.

De 2002 em diante, as fisionomias savânicas e campestres passam a responder por pouco mais da metade da incidência de queimadas nas áreas de Cerrado, chegando a representar 63\% das queimadas, conforme visto nos anos de 2012.

Ao longo da série temporal não se identifica uma tendência estatisticamente significativa de elevação ou diminuição da incidência de queimadas sobre as distintas classes de cobertura e uso do solo. Contudo, ao considerar, conjuntamente, a quantidade de focos de queimadas sobre as formações savânicas e campestres, há uma tendência moderada $\left(\mathrm{R}^{2}=\right.$ $0,41)$ de incremento no decorrer dos anos.

Vale ressaltar que essas formações (savânica e campestre) são mais propensas a ocorrência e propagação de queimadas devido, entre outros fatores, a presença de gramíneas que produzem combustível fino e aerado altamente inflamável durante a estação seca (Bond e Keeley, 2005). 


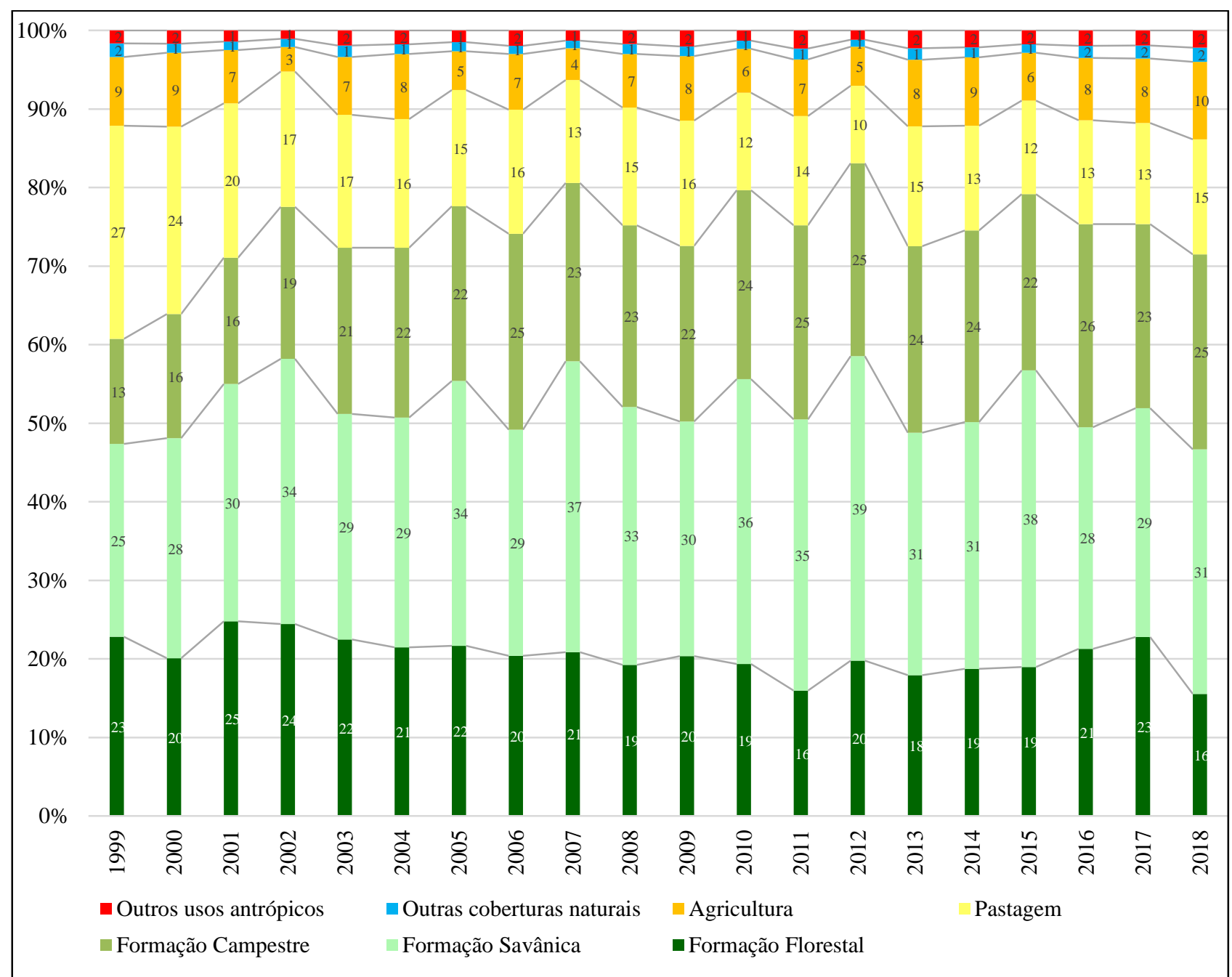

Figura 10 - Incidência de focos de queimada sobre as principais classes de cobertura e uso do solo no bioma Cerrado entre 1999 e 2018

Fonte: BDQueimadas/INPE e Mapbiomas, calculado em SIG e organizado pelos autores.

A respeito desse cenário preocupante, Miranda e colaboradores (2002) complementam que no Cerrado predominam as queimadas superficiais, que consomem principalmente as espécies herbáceas, bastante comuns nas fitofisionomias campestres de campo limpo e sujo. A Figura 11, que ilustra o incêndio que consumiu 65 mil hectares do Parque Nacional da Chapada dos Veadeiros (equivalente a $25 \%$ de sua área), na região nordeste de Goiás, em outubro de 2017, serve justamente para demonstrar a maior propensão de ocorrência e de propagação de queimadas nas fisionomias campestre, que predomina na região nordeste de Goiás.

Contudo, por apresentar uma vegetação evoluída, adaptada e dependente do fogo, o Cerrado apresenta considerável resiliência e uma grande capacidade de regeneração em algumas espécies florísticas do Cerrado. Essa peculiar característica tem sido observada desde o século XIX, pelo naturalista francês Augusto de SaintHillaire, e lembrada por Coutinho (1976).

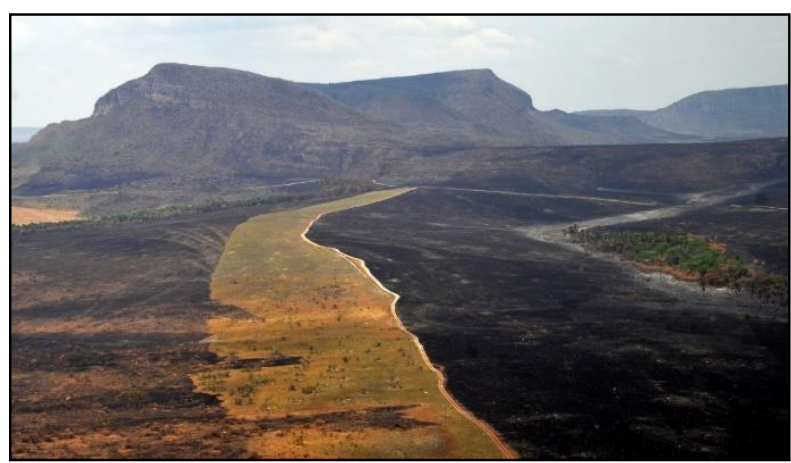

Figura 11 - Fotografia aérea da queimada que consumiu 65 mil hectares do Parque Nacional da Chapada dos Veadeiros, na região nordeste de Goiás, em outubro de 2017.

Fotografia: Tony Winston/Agência Brasília. 
Guedes (1993) salienta a evidência de troncos fortemente suberizados em algumas espécies arbóreas do Cerrado que agem como isolante térmico durante eventos de queimadas. Fidelis e colaboradores (2019) também lembram a impressionante capacidade de regeneração da Bulbostylis paradoxa, uma erva perene da família Cyperaceae, popularmente conhecida como cabelo-de-índio, que inicia sua floração em apenas 24 horas após a ocorrência de uma queimada (controlada) capaz de reduzi-la a um toco carbonizado, havendo a formação completa de flores aptas à polinização em pouco mais de uma semana, conforme visto na Figura 12.

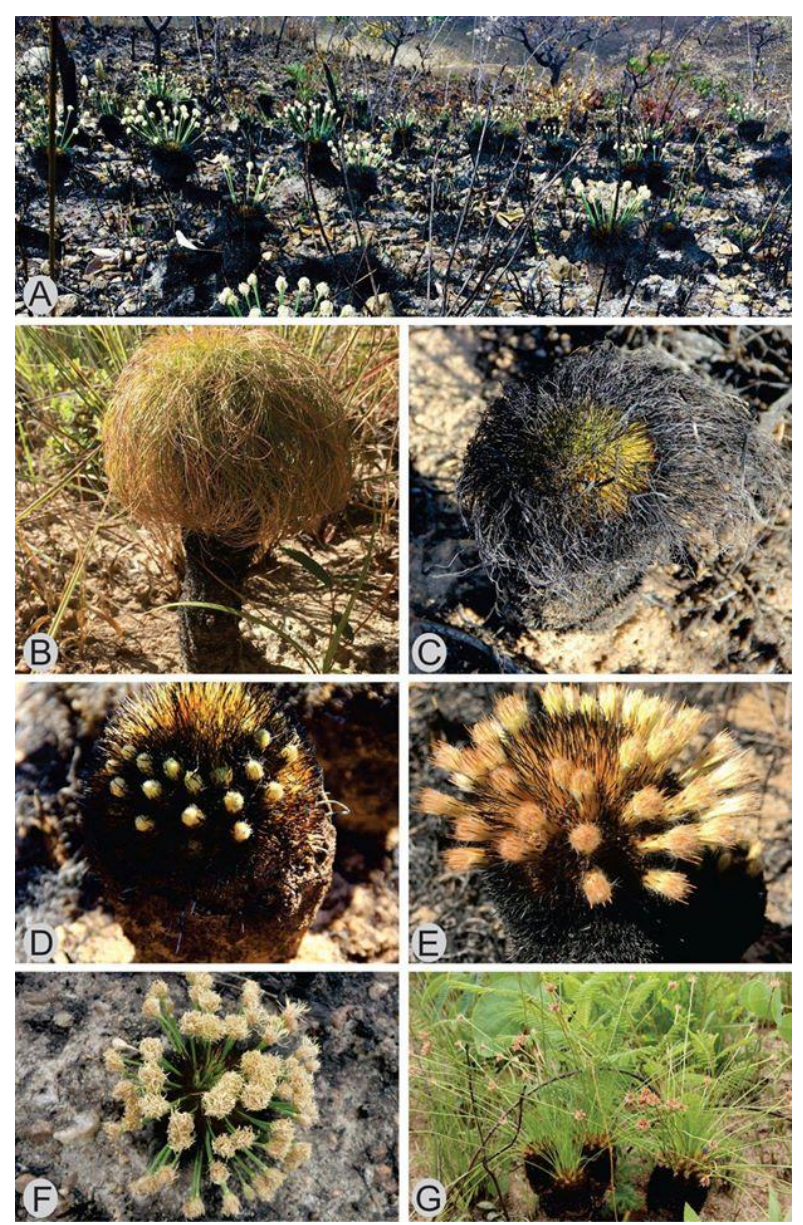

Figura 12 - Após um evento de queimada controlada (A), a sequência de imagens demonstra a condição da Bulbostylis paradoxa (B) logo após o evento (C) e ao longo das 24 horas (D), 48 horas (E), 15 dias $(\mathrm{F})$ e 40 dias $(\mathrm{G})$

Fonte: Fidelis et al. (2019).

Contudo, não se deve generalizar essa capacidade regenerativa a todas espécies do Cerrado, como é o caso de algumas espécies muito sensíveis ao fogo, encontradas em fitofisionomias de mata galeria e de veredas (Borges et al., 2016).

Assim, o fogo utilizado corriqueiramente como instrumento para renovação e manutenção de pastagem e/ou de áreas agrícolas, recorrentemente, tem avançado e atingido as coberturas vegetais do Cerrado, que reagem distintamente conforme suas características fitofisionômicas, umas mais propícias e adaptadas (savânica e campestre) e outra mais resistentes, porém mais sensível, às queimadas (florestal). Dessa forma, recomenda-se que a prática de queimadas deve ser controlada e realizada sob o aporte de técnicas conservacionistas.

\section{Considerações finais}

Instituições governamentais, como o caso do Instituto Nacional de Pesquisas Espaciais (INPE), cumprem um importante papel ao país, subsidiando dados e informações essenciais ao monitoramento ambiental, à realização de atividades de físcalização e à formulação de políticas públicas. No presente trabalho, dados compilados a partir do Banco de Dados de Queimadas (BDQ/INPE), registrados no Bioma Cerrado, no período de 1999 a 2018, demonstraram a ocorrência média de 65.513 focos anuais, mas que podem atingir quantidades surpreendentes, como 137.918 focos, conforme registrado em 2007. Há uma expressiva concentração das queimadas no período seco, especialmente no trimestre agosto-setembro-outubro, que responde por cerca de $72 \%$ das ocorrências anuais. Ao longo dos anos, a maior quantidade de queimadas ocorre principalmente nos estados de Maranhão, Tocantins e Mato Grosso, exatamente ao longo da fronteira agrícola na região do MATOPIBA e próxima ao Arco do Desmatamento, na região de ecótono entre Cerrado, Amazônia e Pantanal.

Também foram de suma importância os mapeamentos de cobertura e uso do solo do Cerrado elaborados pelo Projeto MapBiomas, que compõe uma rede colaborativa entre instituições governamentais e não-governamentais que divulgam numa plataforma virtual a série histórica de mapas anuais de cobertura e uso da terra dos biomas brasileiros. A partir da intersecção do mapeamento do Cerrado com os focos de queimadas, foi possível verificar que cerca de $76 \%$ das queimadas no Cerrado incidem sobre as coberturas naturais, dos quais, cerca de metade incide sobre as formações savânica e campestres. Dentre os usos antrópicos, a maior incidência é 
sobre áreas de pastagem (16\%), com considerável ocorrência também em áreas agrícolas.

Dessa forma, os dados demonstram um padrão espacial de distribuição das queimadas em regiões específicas, uma concentração em período definido e reduzido do ano e também de incidência sobre determinadas classes de cobertura e uso do solo, fornecendo fortes indícios que corroboram a tese de que as queimadas não ocorram de forma aleatória e homogênea, mas associada, principalmente, às coberturas naturais propícias ao desmatamento e à implantação de atividades agropecuárias.

Todavia, devem ser providenciados estudos complementares, no sentido de verificar se nos locais de incidência dos focos de queimadas realmente houve a conversão de cobertura vegetal natural para usos antrópicos nos anos subsequentes - análise essa que pode ser realizada de forma automatizada por técnicas de geoprocessamento. Com a sugestão de averiguações em campo para confrontação e validação dos dados e informações.

Além disso, convém associar a distribuição espaço-temporal das queimadas às variáveis e condicionantes climáticas, tais como a variabilidade da precipitação, da umidade e temperatura do ar e a ocorrência de descargas elétricas, por exemplo, capazes de provocar as queimadas naturais (ou espontâneas) ou de impulsionar as queimadas antrópicas.

Por fim, vale frisar que a adoção de medidas sustentáveis de exploração e de estratégias de conservação do Cerrado não são apenas necessárias, mas, sobretudo, urgentes. É preciso reconhecer e valorizar o Cerrado a partir de sua rica biodiversidade e de sua cultura milenar, materializado nos saberes e ritos dos povos tradicionais.

No contexto das queimadas, salienta-se que para o manejo racional do fogo deve ser levado em consideração tanto o comportamento do fenômeno (fogo) quanto as características de resiliência e fragilidade dos distintos elementos e componentes do ambiente. Assim, medidas preventivas exigem mais do que a simples exclusão desse agente ecológico tão essencial para o Cerrado.

\section{Referências}

Barbosa, A.S., 2015 Um Bioma em Extinção. Xapuri Socioambiental, 4.
Bond, W.J., Keeley, J.E., 2005. Fire as a global 'herbivore': the ecology and evolution of flammable ecosystems. Trends Ecol. Evol., 20, 387-394.

Borges, S.L., Eloy, L., Schmidt, I.B.. Santos, I.A.dos., 2016. Manejo do fogo em veredas: novas perspectivas a partir dos sistemas agrícolas tradicionais no Jalapão. Ambiente \& Sociedade, São Paulo, 19, 269-294.

Clarke, S., French, K., 2005. Germination response to heat and smoke of 22 Poaceae species from grassy woodlands. Australian Journal of Botany, 53, 445-454.

Coutinho, L.M., 2006. O conceito de bioma. Acta Bot. Bras., 20.

Coutinho, L.M., 1976. Contribuição ao conhecimento do papel ecológico das queimadas na floração de espécies do Cerrado. Tese (Livre Docência em Ecologia Vegetal). São Paulo, Universidade de São Paulo.

Fidelis, A., Rosalem, P., Zanzarini, V., Camargos, L.S., Martins, A.R., 2019. From ashes to flowers: a savanna sedge initiates flowers $24 \mathrm{~h}$ after fire. Ecology, 100.

Fonzar, B.C.C., 1994. A circulação atmosférica na América do Sul: os grandes sistemas planetários e subsistemas regionais que atingem o continente: localização e trajetórias. Caderno de Geociências, 11, 11-33.

Guedes, D.M., 1993. Resistência das árvores do Cerrado ao fogo: papel da casca como isolante térmico. Dissertação (Mestrado em Ecologia). Brasilia, Universidade de Brasília.

Hughes, R., 2019. Amazon fires: what's the latest in Brazil? BBC. Disponível em: $<$ https://www.bbc.com/news/world-latinamerica-49971563>. Acessado em 18 novembro de 2019.

INMET. Instituto Nacional de Meteorologia, 2018. Normais Climatológicas do Brasil 1981 - 2010. Brasília-DF.

Klink, C.A., Machado, R.B., 2005. A conservação do cerrado brasileiro. Megadiversidade, 1, 147155.

Kottek, M. et al., 2006. World Map of the KoppenGeiger climate classification update. Meteorologische Zeitschrift, 15, 259-263.

Medeiros, M.B., Miranda, H.S., 2005. Mortalidade pós-fogo em espécies lenhosas de campo sujo submetido a três queimadas prescritas anuais. Acta Botanica Brasilica, 19, 493-500.

MMA. Ministério do Meio Ambiente, 2010. Plano de Ação para prevenção e controle do desmatamento e das queimadas no Cerrado: $1^{a}$ fase (2010-2011). MMA, Brasília. 
MMA. Ministério do Meio Ambiente, 2014. Plano de Ação para prevenção e controle do desmatamento e das queimadas no Cerrado: $2^{\mathrm{a}}$ fase (2014-2015). MMA, Brasília.

MMA. Ministério do Meio Ambiente, Plano de Ação para prevenção e controle do desmatamento e das queimadas no Cerrado: $3^{\text {a }}$ fase (2016-2020). MMA, Brasília.

Miranda, A.C., Miranda, H.S., Dias, I.F.O., DIAS, B.F.S., 1993. Soil and air temperatures during prescribed cerated fires in Central Brazil. Journal of Tropical Ecology, 9, 313-320.

Miranda, H.S.; Bustamante, M.M.C.; Miranda, A.C., 2002. The fire factor, in: Oliveira, P. S.; Marquis, R. J. (eds.). The cerrados of Brazil. Columbia University Press, New York, NY, pp. 51-68.

Mittermeier, R.A., Gil, P.R., Hoffmann, M., Pilgrim, J., Brooks, T., Mittermeier, C.G., Lamoreux, J., Fonseca, G.A.B., 2004. Hotspots revisited: earth's biologically richest and most endangered terrestrial ecoregions. CEMEX, México City.

Monteiro, C.A. de F., 1951. Notas para o estudo do clima do Centro-Oeste brasileiro. Revista Brasileira de Geografia, 13, 3-46.

Nascimento, D.T.F., Araújo, F.M.; Ferreira Júnior, L.G., 2010. Análise dos padrões de distribuição espacial e temporal dos focos de calor no bioma Cerrado. Revista Brasileira de Cartografia, 63, 461-475.

Nascimento, D.T.F., Novais, G.T., 2020. Clima do Cerrado: dinâmica atmosférica e características, variabilidades e tipologias climáticas. Élisée Revista De Geografia Da UEG, 9.

Nascimento, M.A.L.S.do., 2002. O meio físico do cerrado: revisitando a produção teórica pioneira, in: Almeida, M.G.de (org.). Abordagens geográfica de Goiás: o natural e o social na contemporaneidade. IESA, Goiânia, pp. 47-89.
Nimer, E., 1989. Climatologia do Brasil. IBGE, Rio de Janeiro.

Nogueira, E.M., Fearnside, P.M., Nelson, B.W., França, M.B., 2007. Wood density in forests of Brazil's 'arc of deforestation': implications for biomass and flux of carbon from land-use change in Amazonia. For Ecol Manage, 248, 119-135.

Nogueira, E.M., Nelson, B.W., Fearnside, P.M., França, M.B., Oliveira, A.C.A., 2008. Tree height in Brazil's 'arc of deforestation': shorter trees in south and southwest Amazonia imply lower biomass. For Ecol Manage, 255, 2963 2972.

Projeto MapBiomas - Coleção 4.0 (1985-2018) da Série Anual de Mapas de Cobertura e Uso de Solo do Brasil. Disponível em <http://mapbiomas.org/> Acessado em 19 set. 2019.

Ribeiro, J.F., Walter, B.M.T., 2008. As Principais Fitofisionomias do Bioma Cerrado, in: Sano, S.M., Almeida, S.P., Ribeiro, J.F. (Org.). Cerrado: ecologia e flora. Embrapa Informação tecnológica, Brasília, DF, pp.151-212.

Santos, P.R., Pereira, G., Rocha, L.C., 2014. Análise da distribuição espacial dos focos de queimadas para o bioma Cerrado (2002-2012). Caderno de Geografia, v. 24, 133-142.

Serra, A.; Ratisbonna, L., 1942. As massas de ar na América do Sul. Serviço de Meteorologia, Ministério da Agricultura, Rio de Janeiro.

Silva, E.B.da. 2013. A dinâmica socioespacial e as mudanças na cobertura e uso da terra no bioma cerrado. Tese (Doutorado em Geografia). Goiânia, Universidade Federal de Goiás, Goiânia.

Vieira Filho, J.E.R., 2016. Expansão da fronteira agrícola no Brasil: desafios e perspectivas. Ipea, Rio de Janeiro. 